\title{
Pengembangan E-Book Berbasis Android dengan Soal HOTS untuk Membantu Menganalisis Besaran Pada Materi Gerak Lurus
}

\author{
Wahyudha Tri Setiyoaji, *Edi Supriana, Yoyok Adisetio Laksono \\ Jurusan Fisika, Universitas Negeri Malang \\ *Email: edisupriana@yahoo.com
}

Received: 25 Februari 2020;

Accepted: 9 April 2020;

DOI: http://dx.doi.org/10.29303/jpft.v6i1.1725

Published: 24 April 2020

\begin{abstract}
The integration between interactive media and HOTS question could give a big impact on learning process in class room, especially on learning interest and student concept understanding. Android is a learning media that could save more information and questions like ebook. This study was conducted to determine the feasibility of an Android-based electronic book with High Order Thinking Skills to Help Students Analyze Amounts on Straight Motion Material. This research method was used in the ADDIE model (analysis, design, development, implementation, and evaluation). The electronic book was tested for validation by the validator with an average value of 3.94 and the module readability test with respondents of 25 students who obtained an average value of $96 \%$. Based on the data obtained, it can be conclude that the electronic book has decent criteria.
\end{abstract}

Keywords: Electronic Media; Linear Motion; Android

\section{PENDAHULUAN}

Gerak lurus merupakan salah satu materi fisika yang sulit dipahami oleh siswa. Salah satu faktor kesulitan siswa adanya pra konsepsi dalam kehidupan sehari - hari yang tidak langsung ditangani sehingga menjadi miskonsepsi siswa yang berkepanjangan (Pujianto, 2013). Menurut beberapa penelitian yang dilakukan sebelumnya, siswa mengalami miskonsepsi mengenai percepatan, kelajuan, dan kecepatan (Shaffer \& McDermott, 2005); (Singh \& Schunn, 2009); (Paul, 2013) dan menganalisis grafik pada materi gerak lurus (Bunawan, et al. 2017); (Uzun, Sezen, \& Bulbul, 2012). Selain miskonsepsi siswa, ketidak efektifan daya serap siswa terhadap materi gerak lurus dapat terjadi dikarenakan kurang ada media atau alat bantu (Mutia, 2017).

Kesulitan - kesulitan yang dialami siswa dapat diatasi dengan menggunakan media yang mampu membantu siswa dalam menganalisis besaran pada gerak lurus. Salah satunya yaitu dengan menggunakan buku. Penggunaan buku di dalam proses pembelajaran dapat membuat pembelajaran menjadi lebih interaktif (Muhson, 2010) dan lebih efektif (Sunantri, Suyatna, \& Rosidin, 2016). Menurut Peniati Buku dapat membuat siswa lebih tertarik untuk mengikuti proses pembelajaran (Peniati, 2012) sehingga siswa dapat menganalisis besaran pada gerak lurus. Penggunaan buku elektronik merupakan salah satu contoh dari penerapan multimedia intraktif. Buku elektronik ialah buku yang dikemas dalam bentuk elektronik yang memuat audio, foto dan video (Eskawati \& Sanjaya, 2012). Pengintergrasian antara grafik, text, gambar, grafik, dan animasi sehingga informasi yang disampaikan beragam dan lebih kaya akan jika dibandingkan dengan buku konvensional (Triyono, 2012). Kelebihan lain dari buku elektronik bagi pengguna ialah penghematan ruang, mobilitas, kenyamanan atau kemudahan dalam mencari informasi, mudah disimpan dan dicetak dan ramah lingkungan (Anuradha \& Usha 2006); (Noorhidawati \& Gibb 2008) ; $(\mathrm{Wu} \quad \& \quad$ Chen 2011). 
Penelitian sebelumnya yang dilakukan oleh (Taqwa, 2019) menunjukkan bahwa modul elektronik pada materi suhu dan kalor utuk persiapan ujian nasional SMA dinilai dapat memiliki dampak positif pada pemahaman konsep dan minat belajar dalam proses pembelajaran yang mengkaitkan modul elektronik sebagai sarana untuk belajar. Sejalan dengan penelitian (Rahmawati \& Dewi, 2019) tentang penggunaan multimedia interaktif bertujuan untuk meningkatkan prestasi belajar fisika dapat meningkatkan prestasi belajar fisika. Diperkuat dengan penelitian (Herayanti, et $a l ., 2018)$ tentang pengembangan perangkat pembelajaran berbasis masalah menggunakan media moodle untuk meningkatkan keterampilan berpikir kritis mahasiswa pada materi gelombang menunjukkan respon positif terhadap penggunaan moodle yang dikembangkan dan peningkatan hasil berpikir kritis siswa yang dibuktikan dari hasil penelitian menunjukkan adanya peningkatan yang signifikan antara tes awal dan tes akhir.

Selain media yang menunjang dibutuhkan alat yang dapat menganalisis besaran gerak lurus dengan menggunakan soal High Order Thinking Skills (HOTS). Berdasarkan penelitian (Syarifah, et al., 2018) Pembelajaran degan menggunakan soal - soal High Order Thinking Skills (HOTS) dapat melatih kemampuan berpikir kritis peserta didik. Penggunaan metode pembelajaran High Order Thinking Skill (HOTS) memiliki tujuan untuk meningkatkan daya berpikir kritis dalam menerima segala informasi, kemudian dapat meningkatkan cara berpikir kreatif dalam memecahkan suatu permasalahan yang kompleks berdasarkan pengetahuan yang telah didapatkan (Dinni, 2018). High Order Thinking Skills (HOTS) pertama kali dikemukakan oleh (Brookhart, 2010) seorang professor dari Dusquence
University dalam bukunya, 'How to Assess High Order Thingking Skills in Classroom' dia mendefinisikan model ini sebagai metode untuk memperoleh memecahkan masalah (Problem Solving) dan kemampuan berpikir kritis (Critical Thinking). Soal Soal HOTS menekankan pada analisis informasi (Analyzing), evaluasi konsep (Evaluating), dan penciptakan gagasan atau model dari sebuah ilmu pengetahuan (Creating). Jika dibandingkan dengan soal - soal Low Order Thinking Skills (LOTS) yang biasanya ditemui di soal soal Ujian Nasional (UN) yang difokuskan pada ranah pengaplikasian (Applying), pemahaman (Understanding), dan penghafalan (Remembering) (Anderson and Krathwohl, 2009). Penelitian sebelumnya yang dilakukan oleh (Erfan \& Ratu, 2018) tentang pencapaian HOTS (Higher Order Thinking Skills) mahasiswa menunjukkan hasil prestasi mahasiswa dari keterampilan berpikir kognitif yang diperoleh mahasiswa berada dalam kategori rendah 55\%, kategori sedang $11 \%$, dan $34 \%$ dalam kategori tinggi untuk menguasai keterampilan berpikir tingkat rendah (LOTS), sedangkan untuk HOTS , 100\% termasuk dalam kategori rendah sehingga dapat diambil disimpulkan bahwa pencapaian keterampilan berpikir kognitif siswa masih dalam keterampilan berpikir tingkat rendah.

Berdasarkan permasalahan yang telah dipaparkan memerlukan penanggulangan untuk membantu siswa menganalisis besaran pada materi gerak lurus. Penanggulangan ini dapat dilakukan dengan mengembangkan buku elekronik Selain itu siswa diajak untuk memecahkan permasalahan yang berisi soal High Order Thinking Skills (HOTS) sebagai latihan dan evaluasi. buku elektronik yang dikembangkan dapat digunakan dalam mobile device terutama android agar siswa termotivasi untuk belajar dan lebih tertarik. 
Dengan demikian peneliti bertujuan untuk mengembangakan buku elektronik yang berjudul "Pengembangan Buku Elektronik Berbasis Android Dengan Soal High Order Thinking Skills (HOTS) Untuk Membantu Siswa Menganalisis Besaran Pada Materi Gerak Lurus". Produk ini diharapkan dapat memfasilitasi siswa untuk belajar secara mandiri kapanpun dan dimanapun melalui perangkat mobile mereka serta dapat menjadi media yang dapat membantu guru dalam pelaksanaan pembelajaran.

\section{METODE PENELITIAN}

Metode penelitian yang digunakan untuk mengembangkan media ajar yaitu desain ADDIE. Disain ADDIE meliputi Anylisis, Desaign, Development, Implementation, Evaluation. Pada tahap analysis melakukan analisis kinerja dan analisis kebutuhan Tahap desaign dilakukan penyusunan unsur apa saja yang akan dituangkan pada produk, kemudian lanjut ke tahap Development, yaitu tahap merealisasikan produk. Tahap selanjutnya yaitu Implementation yang dilakukan dengan uji coba kepraktisan buku elektronik pada siswa kelas X.

Metode penelitian dilakukan analisis data yang menggunakan teknik analisis data kuantitaif dan kualitatif. Data kuantitatif memuat nilai rata-rata dari penyebaran angket validator. Nilai yang diperoleh akan dirata-rata, kemudian data berupa skala likert. Data kualitatif diperoleh dari perolehan komentar dan saran dari penyebaran instrumen validasi konten dan konstruk. Hal ini bertujuan sebagai pertimbangan untuk dilakukannnya revisi atau tidak. Rumus perhitungan untuk analisis data kuantitatif yaitu

$$
\bar{x}=\frac{\sum_{x}}{n}
$$

Keterangan :

$$
\begin{array}{ll}
\overline{\boldsymbol{x}} & =\text { Nilai rata-rata } \\
\sum_{\boldsymbol{x}} & =\text { Jumlah skor jawaban penilaian } \\
n & =\text { jumlah responden } \quad \text { (Sudjana, 2011) }
\end{array}
$$

Sedangkan kriteria kelayakan media akan beracuan pada Tabel 1 .

Tabel 1. Kriteria Kelayakan Media

\begin{tabular}{cc}
\hline $\begin{array}{c}\text { Nilai } \\
\text { Rata-Rata }\end{array}$ & Kategori \\
\hline $\mathbf{3 , 2 6}-\mathbf{4 , 0 0}$ & Sangat Valid \\
\hline $\mathbf{2 , 5 1}-\mathbf{3 , 2 5}$ & Cukup Valid \\
\hline $\mathbf{1 , 7 6}-\mathbf{2 , 5 0}$ & Kurang Valid \\
\hline $\mathbf{1 , 0 0}-\mathbf{1 , 7 5}$ & Tidak Valid \\
\hline & Sumber : Sudjana, (2011:109)
\end{tabular}

\section{HASIL DAN PEMBAHASAN}

\section{Tahap analyze}

Pada tahap Analyze dilakukan studi dilapangan dengan wawancawa kepada salah satu guru fisika kelas X MIPA yang dilakukan di SMAN 1 Gondanglegi. Hasil wawancara tersebut diperoleh bahwa guru memberikan tugas untuk mencari materi diinternet sebagai tugas awal sisiwa, kemudian siswa memberikan bukti pencariannya di internet kepada guru, selanjutnya guru akan menerangkan di hadapan siswa lainnya disertai sesi tanya jawab. Proses pembelajaran seperti itu kuranglah efektif karena siswa bisa mengakses fitur lain yang ada di handphone seperti media sosial, game dan lainnya.

Saat ini telah banyak media pembelajaran yang dapat membantu siswa agar mudah memahami pembelajaran di dalam kelas, akan tetapi belum adanya soal yang membahas kemapuan berpikir tingkat tinggi kebanyakan soal yang dikerjakan siswa hanya mencakup kemampuan berpikir tingkat rendah.

Media pembelajaran dapat memudahkan seorang guru dalam menjelaskan materi dengan mudah. berdasarkan bahan ajar yang digunakan guru selama ini hanya menggunakan buku cetak yang telah disediakan oleh sekolah sebagai sumber belajar siswa. Disisi lain proses pembelajaran yang di lakukan oleh guru masih menggunakan metode ceramah lalu siswa diberikan sebuah soal. Kurang adanya media yang mendukung berakibat terhadap 
minat siswa untuk belajar Sehingga mempengaruhi kurangnya hasil belajar untuk mencapai ketuntasan minimum sekolah. Pada saat pengerjaan soal hanya terdapat 3-4 siswa yang tuntas dalam ujian.

Setelah melakukan wawancara diperoleh informasi terkait materi fisika yang sulit dipahami oleh siswa antara lain Hukum Bernouli, Hukum Newton Gravitasi, Asas black dan Gerak Lurus. Dengan memepertimbangkan segala aspek sehingga materi yang diambil pada penelitian ini ialah Gerak Lurus.

Buku elektronik ini, dibuat menggunakan Adobe Animate 2020 sebagai media utama dengan bantuan softweree lain seperti Adobe Audition 2020, Adobe Photoshop 2020, Adobe Premier Pro cc 2020, Notepad++ dan Barcode Generator. Berdasarkan hasil analisis diatas diambil kesimpula bahwa diperlkukan Buku elektronik dengan soal High Order Thinking Skills (HOTS) untuk membantu Menganalisis Besaran pada materi Gerak Lurus.

\section{Tahap Design}

Pada tahap Design ini didapatkan berupa kerangka buku elektronik yang akan dikembangkan, ditujukan pada Gambar 1. Pada buku elektronik terdapat 8 fitur. Meliputi aspek Petunjuk Penggunaan, Kompetensi, Pengaturan, Materi, Soal Latihan HOTS, Soal Evaluasi HOTS, Umpan Balik dan Profil Pengembang.

Dalam validasi konten terdapat 3 aspek penilaian yaitu Aspek konten, Aspek materi, Aspek soal HOTS. Pada buku elektronik yang dikembangkan masih terdapat revisi berdasarkn komentar dari Validator. Hasil dari rekapitulasi validasi konten yang diberikan oleh validator ditunjukkan pada Tabel 2.

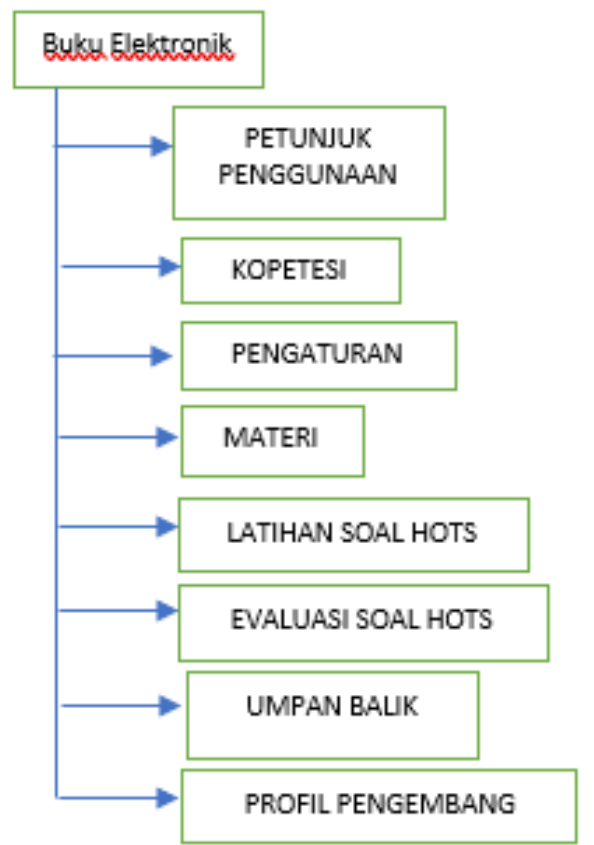

Gambar 1. Kerangka Buku Elektronik

\section{Validasi Aspek Konten}

Hasil validasi konten dari validator, didapatkan hasil validasi oleh ahli materi dengan nilai rata -rata 3,95 dalam kategori sudah valid dan tidak memerlukan revisi. Aspek yang pertama yakni aspek konten meliputi kebenaran reori fisika memperoleh nilai rata - rata 3,92 dalam kategori valid sehinga tidak perlu revisi, aspek yang kedua yakni aspek materi meliputi kesesuaian materi dan kebenaran contoh soal memperoleh nilai rata - rata 4 dalam kategori valid dan tidak memerlukan revisi, dan yang terakhir aspek ketiga yakni Soal HOTS yang meliputi latihan soal dan evaluasi soal memperoleh rata - rata 3,94 dalam kategori valid sehinga tidak perlu revisi dengan masukan untuk lebih teliti lagi dalam penulisan materi agar tidak terjadi kesalahan.

Tabel 2. Hasil Validasi Aspek Konten

\begin{tabular}{cc}
\hline Aspek & Nilai \\
\hline Konten & 3,91 \\
\hline Materi & 4 \\
\hline Soal HOTS & 3,94 \\
\hline
\end{tabular}




\section{Validasi Aspek Konstruk}

Dalam validasi konstruk terdapat 5 aspek penilaian yaitu Aspek Tampilan / tata letak, Aspek Bahasa, Aspek Gambar dan Video, Aspek Usability, dan Aspek Android dan Instalasi. Pada buku elektronik yang dikembangkan masih terdapat revisi berdasarkn komentar dari Validator. Hasil dari rekapitulasi validasi konten yang diberikan oleh validator ditunjukkan pada Tabel 3.

Hasil validasi konstruk dari validator, Aspek yang pertama yakni aspek tampilan / tata letak meliputi tata letak komponen dan navigasi tombol memperoleh nilai rata rata 3,67 dalam kategori valid sehinga tidak perlu revisi, Aspek yang kedua yakni aspek bahasa meliputi Bahasa yang komunikatif, mudah dipahami dan tidak memiliki makna ganda memperoleh nilai rata - rata 3,91 dalam kategori valid dan tidak memerlukan revisi, Aspek yang ketiga yakni aspek gambar dan video meliputi video yang digunakan menarik, mudah dipahami dan sesuai dengan materi yang disajikan memperoleh nilai rata - rata 3,83 dalam kategori valid dan tidak memerlukan revisi, Aspek keempat yakni aspek usability meliputi pengguna mudah menemukan konten yang dituju dengan adanya navigasi memperoleh nila rata - rata 4 dalam kategori valid dan tidak memerlukan revisi, Dan yang terakhir aspek kelima yakni aspek android dan instalasi meleputi dalam hal instalasi tidak rumit dan dapat dijalankan dengan baik pada prakat android memperoleh nilai rata - rata 4 dalam kategori valid dan tidak memerlukan revisi dengan masukan untuk merubah konsep ketika menjawab soal yakni saat pada halaman latihan soal ketika siswa menjawab salah tidak langsung diberikan pembahasan / kunci jawaban melainkan siswa diarahkan ke materi terlebih dahulu lalu bila siswa menjawab yang ke dua kalinya siswa diarahkan kepada pembahasan yang sesuai dengan soal yang dikerjakan.

Tabel 3. Hasil Validasi Aspek Konstruk

\begin{tabular}{cc}
\hline Aspek & Nilai \\
\hline Tampilan / tata letak & 3,67 \\
\hline Bahasa & 3,91 \\
\hline Gambar dan Video & 3,83 \\
\hline Usability & 4 \\
\hline Android dan Instalasi & 4 \\
\hline
\end{tabular}

\section{Tahap Implementation}

Pada tahap Implementation, buku elektronik diuji coba terbatas kepada 25 siswa kelas $\mathrm{X}$ MIPA di SMAN 1 Gondanglegi. Aspek yang dinilai pada uji coba terbatas yakni aspek Tampilan / tata letak, Bahasa, Gambar dan Video, Usability, Motivasi. Penggunaan buku elektronik dikemas semenarik mungkn agar tidak membosankan saat digunakan di dalam pembelajaran diharapkan dapat meningkatkan minat siswa untuk belajar.

Berdasarkan hasil dari validasi dari validator, buku elektronik ini valid dengan revisi dibeberapa bagian. Buku elektronik yang dikembangkan menyajikan materi yang sesuai dengan kompetensi dasar. Contoh soal, latihan soal, dan soal evaluasi yang sesuai dengan IPKD dan mencakup soal soal High Order Thinking Skills (HOTS). Terdapat penambahan tombol keluar di menu utama agar memudahkan pengguna ketika ingin mengeluarka aplikasi. Selain itu, terdapat petunjuk pengoprasian dan pengubahan ikon tertentu di menu di buku elektronik.

Buku elektroik yang dikembangkan memiliki kriteria pertama adaptif, materi yang terdapat di dalam buku masih relevan walaupun terjadi perubahan jaman. Kedua bersifat user friendly yang artinya petunjuk informasi yang terdapat pada buku elektronik dapat membantu pengguna mengoprasikan buku elektronik tersebut. 
Selain itu adanya video praktikum bertujuan untuk menjelaskan maksud dari materi.

\section{Tahap Evaluation}

dari hasil ujicoba keterbacaan yang di tunjukkan pada tabel 4 diperoleh nilai rata rata rekapitulasi sebesar $96 \%$. Dalam skala keterbacaan nilai tersebut menurut arikunto 2006 artinya buku elektronik dengan soal HOTS tersebut dapat terbaca oleh siswa

Tabel 4. Hasil Uji Coba Keterbacaan

\begin{tabular}{cc}
\hline Aspek & Persentase \\
\hline Tampilan / tata letak & $100 \%$ \\
\hline Bahasa & $92 \%$ \\
\hline Gambar dan Video & $96 \%$ \\
\hline Usability & $92 \%$ \\
\hline Motivasi & $100 \%$ \\
\hline
\end{tabular}

\section{PENUTUP}

Penelitian dan pengembangam yang dilakukan menghasilkan produk akhir berupa buku elektronik berbasis android dengan Soal High order Thinking Skills (HOTS) materi Gerak Lurus. Aplikasi buku yang dikembangkan memiliki 8 fitur pada menu utama diantaranya Kompetensi, Materi, Latihan Soal HOTS, Evaluasi Soal HOTS, Pengaturan, Evaluasi Media, Bantuan, Pengembang. Produk yang telah dikembangkan diuji validasi oleh validator, yang memperoleh nilai rata - ratase besar 3,83 Selain itu dilakukan uji keterbacaan dari 25 siswa memperoleh nilai rata - rata sebesar $96 \%$. berdasarkan data yang diperoleh media berupa buku elektronik dapat dikatakan layak.

Pada pengembangan buku elektronik ini ada beberapa yang perlu diperhatikan diantaranya : 1) mempersiapkan materi yang akan diambil, mempersiapkan soal, memperhatikan IPKD, dan pedoman penyusunan materi 2) mengetahui karakteristik dalam penusunan buku elektronik 3) memilih softwere yang akan dipakai dan mengetahui capa pembuatan aplikasi, sebelum diaplikasikan ke dalam skala besar, buat dalam skala kecil hingga bisa digunakan dalam aplikasi tersebut. Pengembagan buku elektronik hanya terbatas pada uji validitas dan uji keterbacaan. Pengembangan produk ini dapat dilakukan dengan cara uji efektifitas pada proses pembelajaran.

\section{REFERENSI}

Anderson, \& Krathwohl. (2009). A revision of Bloom's Taxonomy. American Journal of Psychology. https://doi.org/10.1207/s15430421tip 4104

Brookhart, S. M. (2010). How to Assess Higher-Order Thinking Skills in Your Classroom. In How to Assess HigherOrder Thinking Skills in Your Classroom. https://doi.org/http://dx.doi.org/10.15 17/17460441.2012.733692

Bunawan, W., Setiawan, A., Rusli, A., \& . N. (2017). Penilaian Pemahaman Representasi Grafik Materi Optika Geometri Menggunakan Tes Diagnostik. Jurnal Cakrawala Pendidikan, 2(2), 257-267. https://doi.org/10.21831/cp.v2i2.4830

Dinni, H. N. (2018). HOTS (High Order Thinking Skills) dan Kaitannya dengan Kemampuan Literasi Matematika. Prisma, Prosiding Seminar Nasional Matematika, 1, 170-176.

Erfan, M., \& Ratu, T. (2018). Pencapaian Hots (Higher Order Thinking Skills) Mahasiswa Program Studi Pendidikan Fisika Fkip Universitas Samawa. Jurnal Pembelajaran Fisika Dan Teknologi, $\quad$ 4(2). https://doi.org/.1037//00332909.I26.1.78

Eskawati, S. Y., \& Sanjaya, I. G. M. (2012). Pengembangan E-Book Interaktif Pada Materi Kimia Semester Genap Kelas. Unnes Physics Education Journal, (2), 46-53. 
Herayanti, L., Gummah, S., Sukroyanti, B. A., Gunawan, G., \& Makhrus, M. (2018). Pengembangan Perangkat Pembelajaran Berbasis Masalah Meggunakan Media Moodle Untuk Meningkatkan Keterampilan Berpikir Kritis Mahasiswa Pada Materi Gelombang. Jurnal Pendidikan Fisika Dan Teknologi, 4(2), 158. https://doi.org/10.29303/jpft.v4i2.803

Muhson, A. (2010). Pengembangan Media Pembelajaran Berbasis Teknologi Informasi. Pendidikan Akuntansi Indonesia, VIII(2), 1-10.

Mutia, S. (2017). Pengaruh Strategi Pembelajaran Aktif Reading Guide Terhadap Kemahiran Membaca Intensif Siswa Kelas VIII Sekolah Menengah Pertama Negeri 4 Tanjungpinang Tahun Pelajaran 2016/2017. E-Journal Universitas Maritim Raja Haji, (6), 67-72.

Paul, S. (2013). Miskonsepsi dan Perubahan Konsep dalam Pendidikan Fisika. Miskonsepsi Dan Perubahan Konsep Dalam Pendidikan Fisika. https://doi.org/10.1177/13684310187 60947

Peniati, E. (2012). Pengembangan Modul Mata Kuliah Strategi Belajar Mengajar Ipa Berbasis Hasil Penelitian Pembelajaran. Jurnal Pendidikan IPA Indonesia, 1(1), 8-15.

Pujianto, A. (2013). Analisis Konsepsi Siswa Pada Konsep Kinematika Gerak Lurus. Ejurnal Pendidikan Fisika Tadulako, 1(1), 16-21. Retrieved from http://jurnal.untad.ac.id/jurnal/index.p hp/EPFT/article/view/2370

Rahmawati, A. S., \& Dewi, R. P. (2019). Penggunaan Multimedia Interaktif (MMI) Sebagai Media Pembelajaran Dalam Meningkatkan Prestasi Belajar Fisika. Jurnal Pendidikan Fisika Dan Teknologi, $5(1)$. https://doi.org/http://dx.doi.org/10.29 303/jpft.v5i1.958

Shaffer, P. S., \& McDermott, L. C. (2005). A research-based approach to improving student understanding of the vector nature of kinematical concepts. American Journal of Physics, 73(10), 921-931. https://doi.org/10.1119/1.2000976

Singh, C., \& Schunn, C. D. (2009). Connecting Three Pivotal Concepts in K-12 Science State Standards and Maps of Conceptual Growth to Research in Physics Education. Journal of Physics Teacher Education.

Sunantri, A., Suyatna, A., \& Rosidin, U. (2016). Pengembangan Modul Pembelajaran Menggunakan Learning Content Development System Materi Usaha dan Energi. Jurnal Pembelajaran Fisika, 4(1), 107-117.

Syarifah, T. J., Usodo, B., \& Riyadi. (2018). Higher Order Thingking (HOT) Problems To Develop Critical Thinking Ability And Student Self Efficacy In Learning Mathematics Primary Schools. National Seminar on Elementary Education (SNPD 2018), 1(Snpd), 917-925.

Taqwa, M. R. A., Utami, Y. A., \& Rivaldo, L. (2019). Pengembangan Buku Siswa Elektronik Berbasis Android Pada Materi Suhu Dan Kalor Untuk Persiapan Ujian Nasional SMA / MA. Jurnal Riset Dan Konseptual, 4(1), 225-234.

Uzun, M. S., Sezen, N., \& Bulbul, A. (2012). Investigating Student's Abilities Related to Graphing Skill. Procedia Social and Behavioral Sciences, 46(1990), 2942-2946. https://doi.org/10.1016/j.sbspro.2012. 05.594

Wu, Ming-der \& Chen, Shih-chuan. 2011. Graduate students> usage of and attitudes towardse-books: experiences from Taiwan. Program: Electronic Library and Information Systems.45 (3): 294 - 307. 